\title{
Organisational Decision-Making and Academic Institutions
}

\author{
Ivana Ilijašić Veršić*
}

\begin{abstract}
Changes in understanding and interpretation of decision-making processes have shed more light on complex interplay given the different settings, and different actors. The limitations in human decision-making and their significance and long-term implications on organizational management or policy making inspired a large body of evidence and research. Exploration of decision-making processes spans over decades, and is closely connected to the role of power; the amount of power in organizations is usually joined by the knowledge and prior experience, which together play a significant role in decision-making process, as well in selection of candidates for the job. However, there is an evident void concerning publications on decision-making processes in academic institutions, and it rapidly becomes the focus of interest due to a specific opposition contained in its core; positions of high level administrators are held by the university professors with no mandatory previous experience and/or knowledge in organisational management.
\end{abstract}

Keywords: decision-making; academic institutions; organisations

JEL Classification: D87, D89, D91

\section{Introduction}

People face a huge variety of decisions every day; from which shoes to wear, to whom to marry, or what university to be enrolled in. In the past, the history of research of everyday judgements was greatly influenced by the classical model of rational choice. This model has been applied mostly in economics, but its influence was widely spread and still exists in most behavioural and social sciences, as well as in the fields of law or medicine. According to this model, people are the 'rational actors' who make decisions by assessing the probability of each given option's possible outcome, along with the utility that is to be derived from each. The winning option is the one with the optimal combination of probability and utility (Gilovich and Griffin, 2002). Theory of rational choice assumes that people do rather well in the process.

\footnotetext{
* Ivana Ilijašić Veršić is at CESSDA ERIC, Bergen, Norway.
} 
However, decision-making research from the mid 20th century onwards suggested that people's assessments of likelihood and risk do not conform to the laws of probability. Furthermore, significance of empirical evidence was demonstrated in the past by the surveys that showed the discrepancy between the assessments and the actual performance (Meehl, 1954, and Gilovich and Griffin, 2002), and the fact that intuitive judgements do not exactly correspond to the 'ideal' normative standards (Edwards, 1968 in Gilovich and Griffin, 2002). Simon (1957) offered the most significant theoretical development with the notion that 'full rationality', implied by the rational choice model, was the unrealistic standard for human judgement; he proposed more limited criteria for actual performance (the bounded rationality) that acknowledged the limitations of the human mind. According to his model, people reason and choose rationally, but only within the constraints imposed by their limited search and computational capacities (Gilovich and Griffin, 2002). Daniel Kahneman and Amos Tversky further developed and demonstrated the idea of bounded rationality based on heuristics and biases in their Prospect theory (1979).

The limitations in human decision-making and their significance and long-term implications in organizational and governmental institutions' management or policy making, inspired a large body of evidence and research in certain areas; the research of decision-making processes in organizations has quite a history, and is closely connected to the role of power in organizational decision-making. The amount of power in private sector organizations is usually joined by the knowledge of management and prior experience, which together play a significant role in decision-making process, as well in selection of candidates for the job.

Nevertheless, when it comes to the universities/faculties, there is a huge void concerning publications on decision-making processes. The particularity of the management of the academic institutions in its core contains the opposition; positions of high level administrators are held by the university professors with no mandatory previous experience in managing large organisations.

\section{Decision-Making Theories}

One of the longest lasting is the economic theory of expected utility that was first proposed by Daniel Bernoulli (1738). Bernoulli was intrigued by how much a rational individual is prepared to pay in order to enter a gamble. It was perceived that gamblers would pay expected value of the gamble, but nothing more. However, based on an example of throwing coins ${ }^{1}$, Bernoulli concluded that individuals are prepared to pay a small amount of money for this type of gambles, indicating that individuals exchange monetary value bets for some kinds of 'utilities' (Suhonen, 2007).

One of the key features of the decision-making field is its multidisciplinarity, since several basic and different ideas inspired most prominent research. Stemming 
from economic sciences, but also mathematics and physics, early theories assumed humans as fully rational actors aiming at maximising their utilities. However, in the preface of the first edition of his 'Principles of Economics' written in September 1890, Alfred Marshall explained that 'Economic laws and reasonings in fact are merely a part of the material which Conscience and Common-sense have to turn to account in solving practical problems, and in laying down rules which may be a guide in life' (Marshall, 1920), opening door for other disciplines to offer solutions and answers to some of basic inquires of the process. Decision-making theories made their way from involving other disciplines than economics into the decision-making process, to rather complex variations taking into account uncertain conditions, biases, and risk perceptions as major determinants.

\section{Homo Economicus and Introduction of Bounded Rationality}

Decision-making has puzzled scientists from different fields for centuries. Stemming from economic sciences, early theories assumed humans as fully rational actors aiming at maximising their utilities. At the turn of the $20^{\text {th }}$ century, political economy dealt with 'homo economicus' who was under no influence of ethical concerns, completely rational, acting mechanically and driven purely selfishly. Classical or Expected Utility Theory (EUT) could have handled a wide range of situations where uncertainty and guessing did not play an important role. However, when situations involving decision-making under uncertainty and imperfect competition were examined, an idea for replacing the classical theory by a model of bounded rationality began to emerge (Simon, 1978). The complexity and instability of environment became a central feature of choices that economic man faced. In order to explain human behaviour within a complex and changing environment, the theory must have described a person as more than an adaptive mechanism. While EUT was a rather simple in explanation of human behaviour, behavioural theory of bounded rationality (irrationality) proposed by Simon, argued that the amount of information surrounding people is so vast and complex that people are challenged to organise it, formulate problems, and choose appropriate solutions. Complexity of environment and limited human computational capacities fit the general term of 'bounded rationality'.

\section{Empirical Studies}

Empirical studies offered more evidence of violation of perfect rationality and utility maximisation. Organizational decision-making was the first one observed, and those early studies were mostly conducted by anthropologists who focused on describing decision-making procedures and processes. Economic surveys also started in the 1950s i.e. about the use of accounting data in decision-making in large corporations, 
followed by a series of studies on policy decisions in a number of companies by Cyert, Simon and Trow (1956). With a huge number of research done by economists in the domain in Europe and the US, for a long time it remained vastly unexplored, mostly due to costs, time constraints, lack of proper methodology in order to access the decision-making behaviour, etc.

Additionally, a lot of criticism for classical theory has been sparked by experiments, since it has been noticed that decision-makers systematically violate the rationality axioms (Suhonen, 2007). There are several famous paradoxes showing violation of rationality and utility such as Allais paradox ${ }^{2}$, or Common ratio effect, and other paradoxes found in the course of the following decades. One of them is 'preference reversal' reported by Lichtenstein and Slovic (1971). They showed that decision-maker's behaviour was not consistent when monetary values were added to choices; the order of choices and monetary values of the choices were inconsistent with each other. Another paradox is 'the Ellsberg paradox' (1961) showing that that decision-makers could be influenced by additional information in a way that changes their preferences from the certain to the uncertain case, without change in probabilities or in winning prizes.

Such inconsistencies enabled a number of alternatives for decision-making process, and one of the most prominent was 'the Prospect theory'.

\section{The Prospect Theory}

In the following years and decades other social sciences contributed to reveal the influence of complexity and change of environment combined with deeper insight into the mechanisms of decision-making. Probably best-known theory in the recent decades is the Prospect Theory. In 1979, psychologists Daniel Kahneman and Amos Tversky proposed a theory of individual decision making under risk based on experimental findings suggesting that people do not make decisions in a way the Expected Utility Theory (EUT) predicts. They have formulated the Prospect Theory based on human reactions to monetary outcomes and linked probabilities, at the same time stressing how risk representation through simple monetary games also serves as identification of fundamental attitudes towards risk and value. Ultimately, their ground-breaking work was awarded with the Nobel prize in Economics in 2002. The study of human decision-making was irrevocably changed with the introduction of the Prospect Theory, and challenged the dominance of rational models. Furthermore, introduction of heuristics and biases, as reflexive tools helping to make the complex mental problems more manageable, but possibly leading to errors in judgements, sparked an enormous body of research in psychology and influenced other fields like economics, law, political science and management. 


\section{Naturalistic Decision-Making Theories}

The most recent direction in the vast field of decision-making research body belongs to the Naturalistic theories of decision-making (NDM). The most prominent author who marked the beginnings of NDM in early 1990s is Gary Klein (2002). Models and theories within NDM have emerged from rejection of both classical decision theory, as well as decision research based mostly in laboratories; it suggests that both approaches haven't succeeded in explaining the decision-making processes in a real-world context. But these group of theories are also quite distinct from the direction taken by Kahneman and Tversky, and their ground-breaking work with the Prospect Theory. If that direction has focused on what people do wrong, then the second direction or path is focusing on what people do right.

NDM is focusing on what people do right by close examination of the heuristics and the study of expertise, in order to learn more powerful heuristics. According to Lipshitz et al. (2001), NDM is an attempt to understand how people make decisions in real-world contexts that are meaningful and familiar to them. Real-world contexts refer to situations that include dynamic and continually changing conditions, real-time reactions to these changes, ill-defined goals and tasks, time pressure, uncertainty, missing data, significant personal consequences, and experienced decision-makers. Proficient decision-makers in NDM are defined as people with relevant experience or knowledge in the decision-making domain who directly rely on their experience.

\section{Organisational and Academic Decision-Making}

Decision-making has traditionally been viewed as a complex interplay of high-level processes, involving option generation, evaluation of risks and consequences, and choice of a course of action in line with personal preferences (Baron, 2008; Hastie \& Dawes, 2001). Sinclair and Ashkanasy (2002) created a model which assumed that the behaviour-oriented decision-making process was affected by four broad categories: problem characteristics; decision characteristics; personal disposition; and decision-making context.

\section{Managers as Decision-Makers}

Managers see themselves as decision-makers (Laroche, 1995). Many activities in organizations are designed, operated and perceived as decision-making activities, and organization members frequently refer to decisions as realities of their organizational life. Decisions exist in the eyes of managers. Decisions are a significant part of organization processes. Decision-making theories rarely questioned the status of the manager as a decision-maker. The rational model of decision-making (Allison, 1971) 
placed an isolated decision-maker at the heart of the process, up to extent that Nioche (1985) speaks about 'the model of the lone actor'.

In the alternative, realistic view of decision-making, the decision-maker is certainly not always a central character. The political school redefines the decision-making as an actor among other actors (Crozier and Friedberg, 1977). The idea of actors introduces a distance between the decision and the individuals involved: distance in strategic terms, in the way that actors approach the decisions in relation to their interests and positions in the system; distance in terms of power and control, since the actor is only one of the forces that influence the process. Bureaucratic, organizational or behavioural theories of decision-making (Cyert and March 1963; Carter 1971) demonstrate that many decisions are produced without significant and deliberate intervention of human actors. Decision-makers frequently disappear behind routines and automatic processes.

Several theoretical approaches addressed the environment conditions as the key determinant in decision-making in organisations. In a dynamic or uncertain environment, comprehensiveness is doomed to failure since the data are not available, relationships are not obvious, and the future is unpredictable (Goll and Rasheed, 1997). Comprehensive processes are time-consuming, and in a fast-changing environment a slow decision-making process would be clearly inappropriate. Fredrickson (1984) and Fredrickson and Mitchell (1984) empirically demonstrated that rationality, represented by the comprehensiveness of the planning process, is positively related to performance in an industry with a stable environment and negatively related to performance in a dynamic environment. In a subsequent study of the same firms in the same two industries, Fredrickson and Iaquinto (1989) found that these relationships are stable over time and that comprehensiveness exhibits considerable inertia. Within the Naturalistic Decision-Making theories, one of the first references to organizations can be traced back to the work of Beach who provided an image theory of individual decision-making for personal and organizational decisions. The theory states that decision-makers have three images which guide or limit the decisions they make (Beach, 2016): (1) a set of values and beliefs; (2) specific goals to which the decision maker or organization is striving; (3) defined operational plans for reaching the goals. Similar to the NDM framework, Beach stresses goal-oriented behaviour, but also recognizes the importance of merging individual decision-making with other organizational stakeholders. Following up on Beach, Schmitt (2013) reported about the peculiarities of decision-making in the context of business and industrial organizations. Managerial decisions as part of the process in which many other elements of a 'people' nature are equally important, was highlighted as being a key within large organizations. New research directions include the importance of the group and climate of organizations. Need to evaluate decisions in terms of outcomes was also noted, but that the measurement of significant criteria would remain problematic. Also, the exploration of heuristics (Selart et al. 2000) within organizations which 
relate to cognitive rules of thumb in decision-making processes has been examined. Other organizational decision research which has been discussed within the NDM community has included a focus upon management decision-making. Managers are often challenged by factors identified by the NDM framework including: ill-structured problems; uncertain, dynamic environments; shifting, ill-defined or competing goals; action/feedback loops; time stress and high stakes; organizational goals and norms. However, researchers who have explored managers within organizations at the level of individual, group and organization all commonly appear to recognize that different strategies of decision-making are required for organisational effectiveness. It appears that within the context of the organization, and the business world, decision-making research requires a broad approach in order to fully understand the process. Recent evidence of this broadening is evident in research conducted by Klein $(2004,2005)$, beginning to explore the complexities of cultural differences and cognition.

\section{Academics as Decision-Makers}

Higher education area has become an increasingly complex environment, requesting a great extent of devotion and skill from the academic leaders. Unpredictable and changing funding conditions across Europe, and beyond, constant demand for results, more external projects, increased scientific production, exceptional metrics, etc. create an extremely complex environment putting a huge pressure on leaders and forcing them to think in complex ways and to perceive organisational events from a number of different perspectives. Weick's multi-perspective thinking (1979) has introduced the notion that human behaviour is complex enough to generate many different and sometimes conflicting interpretations. With increased information generated by these different perspectives, leaders have a broader view of the organisation, and an increased number of decision-making options. Building on that notion, Del Favero (2006) found that, under some conditions, academic discipline is supported as a factor enabling multi-framing behaviour of deans. However, that cannot be generalized; for a dean who thinks complexly, but is less swift in differentiating between the circumstances where engagement of perspectives is important versus those where perspective taking may be constrained by time-sensitive decisions, can be at a serious disadvantage. It can result in a less effective behaviour despite the ability to think complexly. However, the research on the ability to view complex situations from a variety of perspectives has been seldom.

Wolverton and al. (1999a) reported that work of academic decision makers has long-term effects and consequences, suggesting important implications of this particular role for successful management of academic institutions and facing increasing demands in higher education area. According to them, academic decision makers should be more carefully examined since they occupy the highest position in academic institutions and serve as CEOs of academic administrative operations. The 
positions in academic institutions' managements require daily coping and navigation between academic and managerial activities taking into account the complexity assumed by both roles.

\section{Conclusion}

There is a substantial evidence suggesting corporate managers use both the intuitive and analytical approaches in the decision-making, and that personality plays a part in their decision-making behaviour. Some studies show specific associations between executive functions and cognitively demanding decision-making tasks, as valid indicators of analytic decision-making. However, there is an obvious lack of evidence regarding academic decision-makers. Del Favero (2006) suggest more complex influence of academic discipline on administrative behaviour than expected or perceived before. Faculties and universities are getting increasingly complex as organisations, with effective decision-making processes less clear and predictable. In such circumstances, organisational decision-making could be affected both in process and in content. Academic administrative managers have to adapt in order to streamline the implications for institutional governance and the quality of administrative decisions.

Del Favero findings suggest that academic discipline should also be taken into account as a possible factor in predicting the extent of cognitive complexity associated with the administrative behaviour of academic decision-makers.

\section{NOTES}

\footnotetext{
${ }^{1}$ Bernoulli proved so-called St. Petersburg gamble or paradox - coin is repeatedly thrown until we get heads. Our winning sum is $2 n$, where $n$ is a number of throws until we get the first heads. As there is always a non-zero probability that $n$ can be very large, the winning sum can increase infinitely.

${ }^{2}$ Allais paradox - comparing participants' choices in two different experiments, each of which consists of a choice between two gambles, A and B. The inconsistency stems from the fact that in expected utility theory, equal outcomes (e.g. \$1 million for all gambles) added to each of the two choices should have no effect on the relative desirability of one gamble over the other; they should 'cancel out'.
}

\section{REFERENCES}

Allison, G.T. (1971). The Essence of Decision. Boston, MA: Little Brown.

Baron, J. (2012). The point of normative models in judgment and decision making. Frontiers in Psychology, 3(577), 1-3. DOI:10.3389/fpsyg.2012.00577

Beach, R. and al. (2016). A New Theory of Mind: The Theory of Narrative Thought. Newcastle upon Tyne, UK: Cambridge Scholars Publishing. 
Carter, E.E. (1971). The Behavioral Theory of the Firm and Top Level Corporate Decisions. Administrative Science Quarterly, 16(4), 412-428.

Crozier, M. and Friedberg, E. (1977). L'acteur et le systeme. Paris, France: Seuil.

Cyert, R.M., Simon, H.A. and Trow, D.B. (1956). Observation of a Business Decision. The Journal of Business, 29, 238-247.

Cyert, R.M. and March, J.G. (1963). A Behavioral Theory of the Firm. Englewood Cliffs, NJ: Prentice Hall.

Dawes, R.M., Faust, D., \& Meehl, P.E. (1989). Clinical versus actuarial judgment. Science, 243(4899), 1668-1674.

Dean, J.W. and Sharfman, and M.P. (1993). Procedural rationality in the strategic decision-making process. Journal of Management Studies, 30(4), 587-610. DOI:10.1111/j.1467-6486.1993. tb00317.x

Del Favero, M. (2006). An examination of the relationship between academic discipline and cognitive complexity in academic deans' administrative behaviour. Research in Higher Education, 47(3), 281-315.

Edwards, W., Kiss, I., Majone, G. \& Toda, M. (1984). What constitutes 'a good decision'? Acta Psychologica, 56, 5-27.

Ellsberg, D. (1961). Risk ambiguity, and the Savage axioms. Quarterly Journal of Economics, 75(4), 643-669.

Fredrickson, J.W. (1984). The Comprehensiveness of Strategic Decision Processes: Extension, Observations, Future Directions. The Academy of Management Journal, 27(3), 445-466.

Fredrickson, J.W. and Mitchell, T.R. (1984). Strategic Decision Processes: Comprehensiveness and Performance in an Industry with an Unstable Environment. Academy of Management Journal, 27(2), 399-423.

Fredrickson, J.W. and Iaquinto, A.L. (1989). Inertia and Creeping Rationality in Strategic Decision Processes. The Academy of Management Journal, 32(3), 516-542.

Gilovich, T., Griffin, D. and Kahneman, D. (2002). Heuristics and Biases: The Psychology of Intuitive Judgment. New York, NY: Cambridge University Press.

Goll, I. and Rasheed, A.M.A. (1997). Rational Decision-Making and Firm Performance: The Moderating Role of Environment. Strategic Management Journal, 18(7), 583-591.

Kahneman, D. and Tversky, A. (1979). Prospect theory: An analysis of decision under risk. Econometrica, 47(2), 263-291.

Klein, G. (2002). Intuition at work. New York, NY: Bantam Dell.

Klein, H.A. (2004). Cognition in Natural Settings: The Cultural Lens Model. In M. Kaplan (Ed.), Cultural Ergonomics: Advances in Human Performance and Cognitive Engineering (249-80). Oxford: Elsevier.

Klein, H.A. and McHugh, A.P. (2005). National Differences in Teamwork. In W.B. Rouse and K.R. Boff (Eds.), Organisational Simulation (229-52). Hoboken, NJ: Wiley - Interscience.

Laroche, H. (1995). From Decision to Action in Organizations: Decision-Making as a Social Representation, Organization Science. Focused Issue: European Perspective on Organization Theory, 6(1), 62-75.

Lichtenstein, S. and Slovic, P. (1971). Preference between Bids and Choices in Gambling Decisions. Journal of Experimental Psychology, 89(1), 46-55.

Lipshitz, R., Klein, G., Orasanu, J., and Salas, E. (2001). Taking Stock of Naturalistic Decision Making. Journal of Behavioral Decision Making, 14(5), 331-352. DOI: 10.1002/bdm.381

Marshall, A. (1920). Principles of Economics. Library of Economics and Liberty. Retrieved from: http://www.econlib.org/library/Marshall/marP.html

Meehl, P.E. (1954). Clinical versus statistical prediction: A theoretical analysis and a review of evidence. Minneapolis, Minnesota: University Minnesota Press. 
Nioche, J.P. (1985), La decision, ou l'action strategique comme processus. In J.P. Anastassopoulos et al. Pour une nouvelle politique d'entreprise. Paris, France: PUF.

Selart, M., Boe, O. and Takemura, K. (2000). How Do Decision Heuristic Performance and Social Value Orientation Matter in the Building of Preferences? Göteborg Psychological Reports, 30(6), 1-22. Retrieved from: https://ssrn.com/abstract=2409093

Simon, H.A. (1978). Rational decision-making in business organisations. A Nobel Memorial Lecture, held on 8th December 1978. Economic Sciences, 343-371.

Simon, H.A. (1959). Theories of Decision-Making in Economics and Behavioral Science. The American Economic Review, 49(3), 253-283.

Sinclair, M. and Ashkanasy, N.M. (2002). Intuitive decision-making amongst leaders: More than just shooting from the hip. Mt Eliza Business Review, 5(2), 32-40.

Schmitt, N. (2013). Research in Consulting Psychology Journal: Practice and Research: Reactions and suggestions. Consulting Psychology Journal: Practice and Research, 65(4), 278-283. DOI:10.1037/a0035513.

Suhonen, N. (2007). Normative and Descriptive Theories of Decision Making under Risk: A Short Review. Discussion Papers No. 49, University of Joensuu, Economics. ISBN 978-952-458985-7 ISSN 1795-7885

Weick, K. E. (1979). The Social Psychology of Organizing, (2nd ed.). Reading, MA: Addison-Wesley. Wolverton, M., Gmelch, W.H., Wolverton, M.L., and Sarros, J.C. (1999a). Stress in academic leadership: US and Australian department chairs/heads. Review of Higher Education, 22(2), 165-185. 